\title{
Olfactory discrimination largely persists in mice with defects in odorant receptor expression and axon guidance
}

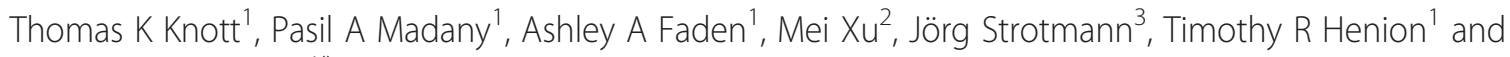
Gerald A Schwarting ${ }^{1 *}$

\begin{abstract}
Background: The defining feature of the main olfactory system in mice is that each olfactory sensory neuron expresses only one of more than a thousand different odorant receptor genes. Axons expressing the same odorant receptor converge onto a small number of targets in the olfactory bulb such that each glomerulus is made up of axon terminals expressing just one odorant receptor. It is thought that this precision in axon targeting is required to maintain highly refined odor discrimination. We previously showed that $\beta 3 \mathrm{GnT}^{-1-}$ mice have severe developmental and axon guidance defects. The phenotype of these mice is similar to adenylyl cyclase 3 (AC3) knockout mice largely due to the significant down-regulation of AC3 activity in $\beta 3 \mathrm{GnT} 2^{-/-}$neurons.

Results: Microarray analysis reveals that nearly one quarter of all odorant receptor genes are down regulated in $\beta 3 \mathrm{GnT}^{-1-}$ mice compared to controls. Analysis of OR expression by quantitative PCR and in situ hybridization demonstrates that the number of neurons expressing some odorant receptors, such as mOR256-17, is increased by nearly $60 \%$ whereas for others such as mOR2 8 the number of neurons is decreased by more than $75 \%$ in $\beta 3 \mathrm{GnT}^{-/-}$olfactory epithelia. Analysis of axon trajectories confirms that many axons track to inappropriate targets in $\beta 3 \mathrm{GnT}^{-/-}$mice, and some glomeruli are populated by axons expressing more than one odorant receptor. Results show that mutant mice perform nearly as well as control mice in an odor discrimination task. In addition, in situ hybridization studies indicate that the expression of several activity dependent genes is unaffected in $\beta 3 \mathrm{GnT}^{-/-}$olfactory neurons.

Conclusions: Results presented here show that many odorant receptors are under-expressed in $\beta 3 \mathrm{GnT}^{-/-}$mice and further demonstrate that additional axon subsets grow into inappropriate targets or minimally innervate glomeruli in the olfactory bulb. Odor evoked gene expression is unchanged and $\beta 3 \mathrm{GnT}^{-/-}$mice exhibit a relatively small deficit in their ability to discriminate divergent odors. Results suggest that despite the fact that $\beta 3 \mathrm{GnT} 2^{-/-}$mice have decreased AC3 activity, decreased expression of many ORs, and display many axon growth and guidance errors, odor-evoked activity in cilia of mutant olfactory neurons remains largely intact.
\end{abstract}

Keywords: Olfactory sensory neurons, B3GnT2, Adenylyl cyclase 3, Axonal convergence

\footnotetext{
* Correspondence: gerald.schwarting@umassmed.edu

${ }^{1}$ Cell Biology Department, University of Massachusetts Medical School, 55 Lake Avenue North, Worcester, MA 01655, USA

Full list of author information is available at the end of the article
} 


\section{Background}

Understanding the organization of connections in the mammalian olfactory system is a challenge because the rules used to generate a map of axon trajectories from the olfactory epithelium to the olfactory bulb (OB) appear to differ considerably from other sensory modalities, such as the visual and somatosensory systems [1-3]. It is now clear that regulation of adenylyl cyclase activity and generation of cAMP is one of the major contributors of guidance information in olfactory axons [4-6]. In fact, much of the influence that was initially attributed to odorant receptors (ORs) themselves has now been shown to result from ORdependent cAMP signaling [7]. In this regard, an important question is how olfactory sensory neurons (OSNs) regulate adenylyl cyclase 3 (AC3) activity, since cAMP is responsible not only for activation of the cyclic nucleotide-gated channel (CNG) in cilia but also for downstream signaling in axons via pathways that may regulate the activities of protein kinase A and the transcription factor, CREB [4].

We have previously shown that the glycosyltransferase $33 \mathrm{GnT} 2$ is expressed in OSNs and is the key enzyme in the synthesis of polylactosamine (PLN) glycans $[6,8,9]$. AC3 is heavily $\mathrm{N}$-glycosylated with PLN glycans in OSNs, and its expression is significantly down-regulated on $\beta 3 \mathrm{GnT} 2^{-/-}$axons [6]. The severe olfactory developmental and axon guidance abnormalities in $\beta 3 \mathrm{GnT} 2^{-/-}$ mice appear in many respects to phenocopy wiring defects described for AC3 knockout mice where olfactory cAMP signaling is also reduced [10-12]. In both models, M72 axons are misguided specifically to multiple heterotypic glomeruli primarily in the ventromedial $O B$, and P2 axons are mostly lost from the postnatal OB. These changes in axon growth and guidance are due in part to the decrease in cAMP-dependent signaling in both mouse models resulting in altered expression of important axon guidance cues, such as neuropilin-1 and semaphorin-3A $[6,13]$.

Despite these many similarities, the major difference between the two mouse models is their respective abilities to detect and discriminate odors. $\mathrm{AC}^{-/-}$mice are anosmic due to the absence of cAMP synthesis and the resulting inability to activate CNG channels in dendritic cilia [14]. In contrast, although AC3 expression is significantly reduced in axons extending to the $\mathrm{OB}$ of $\beta 3 \mathrm{GnT} 2^{-/-}$mice, $\mathrm{AC} 3$ traffics normally to cilia and although reduced amounts of cAMP are produced, adult $\beta 3 \mathrm{GnT} 2^{-/-}$mice are not anosmic $[6,8]$. In order to gain insight into olfactory discrimination in $\beta 3 \mathrm{GnT} 2^{-/-}$mice, we compared OR gene expression, examined axon trajectories by immunocytochemistry with specific OR antibodies, and carried out an odorant discrimination task on WT and $\beta 3 \mathrm{GnT}^{-/-}$ mice. Results presented here show that many OR genes are significantly down-regulated in $\beta 3 \mathrm{GnT} 2^{-1-}$ mice such that only a small number of those axons make connections in the OB. In addition, other OR-specific axon subsets innervate inappropriate targets in the $\mathrm{OB}$. These findings will be discussed in light of the fact that $\beta 3 \mathrm{GnT}^{-/-}$mice can discriminate odors with considerable fidelity.

\section{Results}

\section{Odorant receptor alterations in $\beta 3 \mathrm{GnT} 2^{-/-}$mice}

Five separate samples of OE were dissected from adult $\beta 3 \mathrm{GnT}^{-/-}$mice and littermate controls and mRNA was isolated from each sample. Following preparation of cDNA and labeling, the samples were each hybridized to an Affymetrix Mouse Gene 1.0 ST Array (Afftymetrix, Santa Clara, CA USA). A median value was calculated for each probe set for each OR gene in the 10 samples. Median values of the five null samples were compared pairwise with median values from the five WT samples. A null/WT ratio was generated that represents the mean of the five pairwise comparisons, Of 1,144 probe sets for OR transcripts, results indicated that mRNAs for 867 of the ORs were expressed at similar levels in WT and $\beta 3 \mathrm{GnT}^{-/-}$OEs, including OR37 and M72. Results also indicated that expression of 256 OR genes was decreased by more than $30 \%$ in all five samples obtained from $\beta 3 \mathrm{GnT} 2^{-/-}$OEs compared to the five WT OE samples. In addition, 21 OR transcripts, including mOR 256-17 and mOR $125-1$ were increased by greater than $25 \%$ in all $\beta 3 \mathrm{GnT}^{-/-}$OEs. The null/WT ratios of several of the 21 ORs that were increased the most, and a few of the many other ORs that decreased or were unchanged are presented in Table 1. In order to examine these differences in greater detail, we selected several ORs with mean values that were significantly decreased, increased or about the same in $33 \mathrm{GnT} 2^{-/-}$OEs compared to littermate controls and performed real time RT-qPCR or in situ hybridization analyses.

Using the gene array data as a guide, we chose primer sets for six ORs with null/WT ratios that were either greater than 1.9 or were less than 0.6. After isolating RNA from OE samples, we performed RT-qPCR to find the relative differences in the expression of these ORs (Figure 1). Three ORs, mOR267-17, mOR125-1, and mOR256-7 were analyzed that increased significantly in $\beta 3 \mathrm{GnT}^{-/-}$OEs compared to controls and three ORs, mOR13-4, mOR18, and mOR28 were significantly decreased. qPCR analysis showed that mOR256-17 expression was increased by $71 \%$ in $\beta 3 \mathrm{GnT} 2^{-/-}$OEs compared to controls, and mOR 28 was decreased by $89 \%$, validating the gene array generated values of a $90 \%$ increase for mOR256-17 and a 79\% decrease for mOR28.

As the RT-qPCR results confirmed the gene array analyses that many ORs were either under- or over-expressed in $\beta 3 \mathrm{GnT}^{-/-}$OEs, we made riboprobes to these and other ORs in order to further examine OR gene expression in 
Table 1 Comparison of odorant receptor gene expression in $\beta_{3} \mathrm{GnT}^{-/-}$and WT OEs

\begin{tabular}{ccc}
\hline & Odorant receptor & null/WT \\
\hline Olfr136 & mOR256-7 & $3.0^{*}$ \\
Olfr1370 & mOR256-14 & 2.9 \\
Olfr1259 & mOR232-9 & 2.7 \\
Olfr43 & mOR125-1 & 2.6 \\
Olfr599 & mOR23-1 & 2.5 \\
Olfr1122 & mOR264-1 & 2.4 \\
Olfr131 & mOR256-4 & 2.3 \\
Olfr715 & mOR260-1 & 2.2 \\
Olfr15 & mOR256-17 & 1.9 \\
Olfr156 & OR37b & 0.9 \\
Olfr160 & M72 & 0.8 \\
Olfr151 & M71 & 0.7 \\
Olfr1264 & mOR18 & 0.6 \\
Olfr2 & I7 & 0.5 \\
Olfr640 & mOR13-4 & 0.4 \\
Olfr17 & P2 & 0.3 \\
Olfr1507 & mOR28 & 0.2 \\
\hline
\end{tabular}

*Median values of the ratios obtained by dividing the gene array signal intensities from $\beta 3 \mathrm{GnT} 2$ null OEs by the signal intensities from WT OEs.

these mice, and to quantify the changes in the number of OSNs expressing specific receptors. As a control, to confirm a previous observation [8], the number of neurons expressing the P2 receptor was reduced substantially in $\beta 3 \mathrm{GnT}^{-1-}$ mice compared to WT. In contrast, the number of cells expressing M72 and OR37 showed no evidence of change (Figure 2, Tables 1 and 2). In no case was the distribution of positive neurons within zones and turbinates changed in $\beta 3 \mathrm{GnT}^{-/-}$mice (arrows in Figure 2). RT-qPCR analysis indicated that several receptors were up-regulated in $\beta 3 \mathrm{GnT}^{-/-}$OEs. In situ hybridization studies of these same receptors confirmed that the number of OSNs expressing mOR256-14 (olfr1370), mOR256-17 (olfr15) and mOR125-1 (olfr43) were significantly increased in $\beta 3 \mathrm{GnT} 2^{-/-}$OEs compared to WT OEs (Figure 3 and Table 2).

Interestingly, as is the case in rats [15], the number of cells expressing different ORs varies significantly, often by several fold in WT mice. For example, there are more than 10 times more mOR256- $17^{+}$cells than $\mathrm{M}^{+} 2^{+}$neurons in the adult OE. However, although our sample is small, changes in expression in $\beta 3 \mathrm{GnT} 2^{-/-}$mice do not appear to be related to the absolute number of cells expressing a given OR. For example, although their expression levels are about the same in WT mice, the number of mOR $125-1^{+}$cells increased by about one third in $\beta 3 \mathrm{GnT}^{-/-}$mice, whereas the number of $\mathrm{P}^{+}$ neurons decreased by more than $75 \%$ (Table 2).

\section{Analysis of mOR256-17 axon guidance in $\beta 3 \mathrm{GnT}^{-1-}$ mice} Antibodies to the mOR256-17 odorant receptor were used to map the position of glomeruli in adult OBs. In WT mice, the antibody reacted with axons in the nerve layer and glomeruli within a narrowly circumscribed area of the OB. The antibody consistently labeled two glomeruli on the lateral surface of the $\mathrm{OB}$, midway between the dorsal and ventral extent of the $\mathrm{OB}$. The two immunoreactive glomeruli were always positioned side by side (arrows in Figure 4A). Antibodies to mOR256-17 also reacted with axons in the nerve layer and two glomeruli on the medial surface of the OB. These two medial mOR256- $17^{+}$glomeruli were positioned midway between the dorsal and ventral extent of the $\mathrm{OB}$ and were always side by side, identically to the lateral immunoreactive glomeruli (arrows in Figure 4B). In previous studies, immunocytochemical analysis using this same antibody normally revealed just one lateral and one medial glomerulus per OB [16], although other studies have also found two medial and

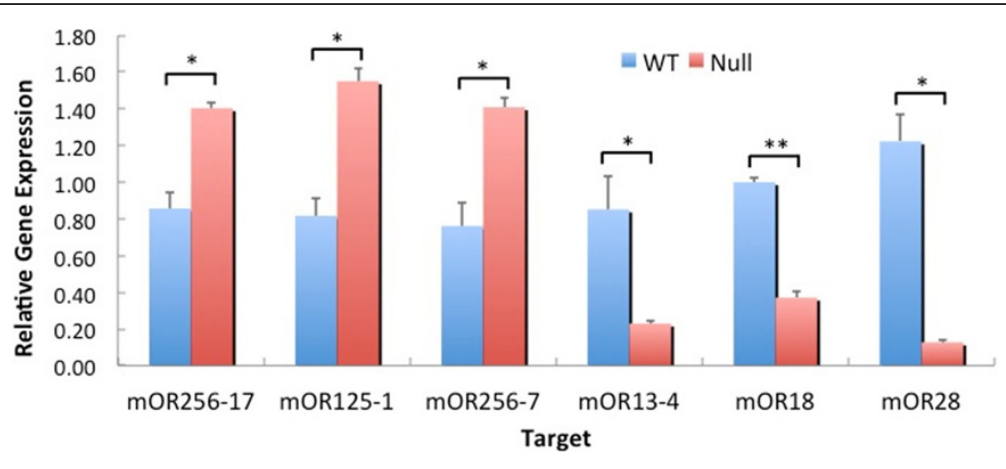

Figure 1 Quantitative PCR analysis for relative expression of ORs. In $\beta 3 \mathrm{GnT} 2^{-/-}$mice the expression of mOR256-17 (Olfr15), mOR125-1 (Olfr43), and mOR256-7 (Olfr136) increased while that of mOR13-4 (Olfr640), mOR16 (Olfr1264), and mOR28 (Olfr 1507) decreased compared to WT mice. Results are the average relative value of three animals normalized to an RNA polymerase 2 reference target. Statistics: Student's $t$ test, ${ }^{* *} P<0.001 .{ }^{*}<0.05$; mean \pm SEM $(n=3)$. 


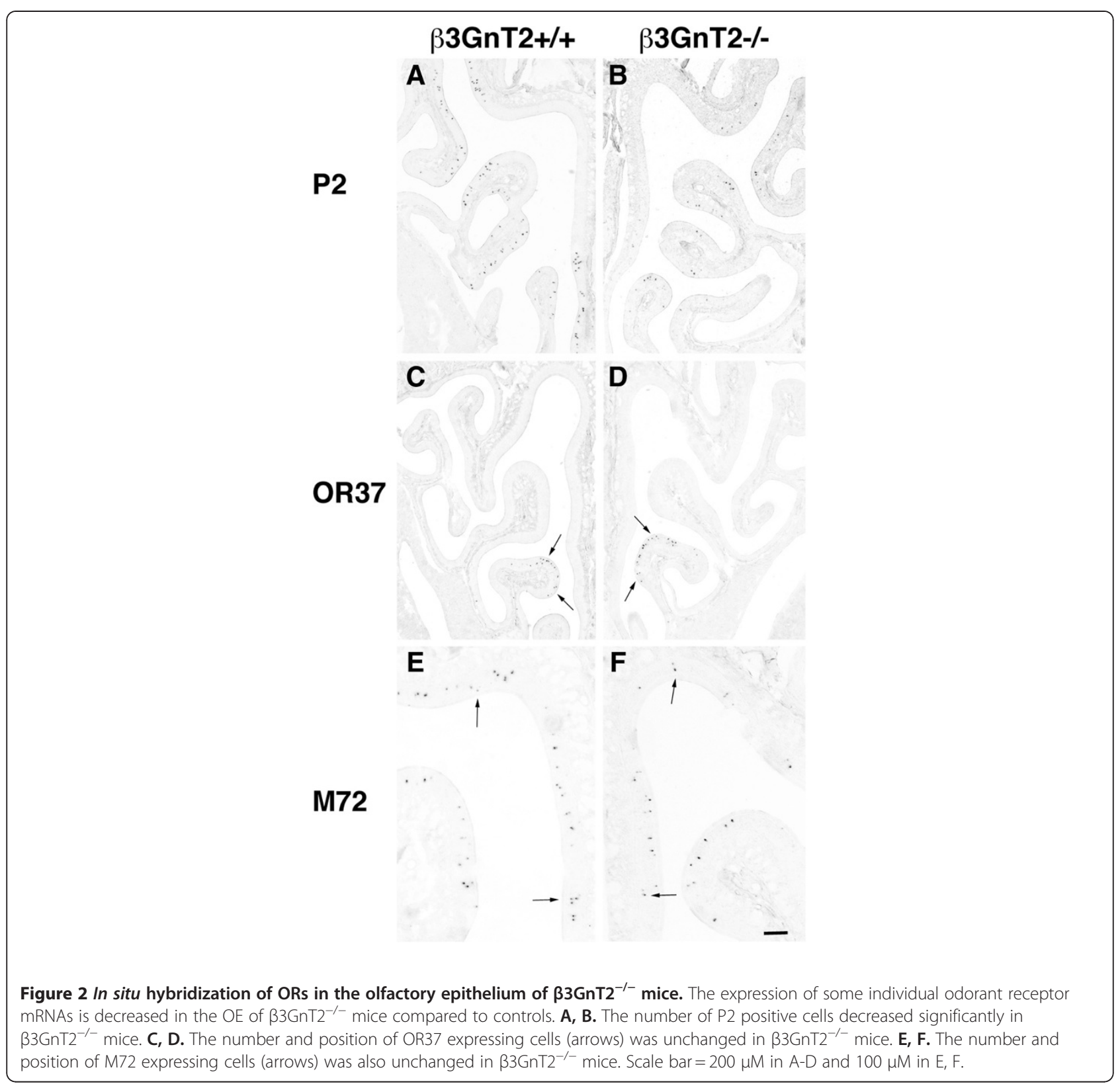

two lateral mOR256-17 ${ }^{+}$glomeruli [17]. It is not clear whether this reveals a second mOR256-17 ${ }^{+}$glomerulus or if the antibody cross-reacts with closely related ORs that normally project to adjacent glomeruli. The total number of mOR256-17 $7^{+}$neurons is a extremely high compared to some other ORs (Table 2), thus it would not be surprising if there is normally more than one mOR256- $17^{+}$glomerulus in each half $\mathrm{OB}$.

In $\beta 3 \mathrm{GnT}^{-/-}$OBs, mOR256-17 immunoreactive glomeruli are present in the OB but in more scattered positions on the lateral and medial surfaces. The mutant OBs are shaped somewhat differently from WT OBs in that they are shorter along the rostrocaudal axis and along the dorsoventral axis but not mediolaterally [8]. In this example, which is typical of four OBs examined, a mOR256-17 immunoreactive glomerulus is present on the lateral surface of the $\mathrm{OB}$ (arrow in Figure 4C) in a position similar to those seen in the wild type OB. Three additional mOR256-17 positive glomeruli are also detected in more caudal sections of the ventral $\mathrm{OB}$ (arrows in Figure 4D, E, F). Even further caudally, three additional mOR256-17 glomeruli are visible in the ventral $\mathrm{OB}$ that appear to represent medially projecting axons (arrows in Figure 4G). One of these mutant glomeruli is in the approximate correct position compared to wildtype $\mathrm{OB}$, but the others are located either more ventrally or 
Table 2 Odorant receptor expression in olfactory sensory neurons

\begin{tabular}{lcccc}
\hline Receptor & $\beta 3 G n T 2+/+$ & $\beta 3 G n T 2-/-$ & \% Change & p value \\
\hline M72 (mOR171-3) & $8,162+/-1,062$ & $8,008+/-1,668$ & $-3.0+/-12.1$ & 0.88 \\
olfr15 (mOR256-17) & $96,389+/-15,250$ & $148,170+/-14,500$ & $+59.0+/-19.8$ & $-8.5+/-12.5$ \\
OR37 (mOR262-14) & $7,579+/-521$ & $7,073+/-1,424$ & $+38.8+/-6.2$ & 0.038 \\
olfr43 (mOR125-1) & $27,896+/-3,550$ & $38,339+/-3,610$ & $+39.8+/-8.77$ & 0.004 \\
olfr1370(mOR256-14) & $15,957+/-1,833$ & $22,161+/-2,183$ & $-78.7+/-1.7$ & 0.04 \\
P2 (mOR263-5) & $25,377+/-1,772$ & $5,396+/-535$ & 0.001
\end{tabular}

To analyze any differences within a slide series, In situ experiments were done using the same probe on two slides from a WT series and two from a null series. These slides were found to have less than $3 \%$ differences in receptor counts for either genotype. Thus, the total amount of receptors for each probe is an extrapolation from counts made on approximately $5 \%$ of the tissue. Statistics are done with a two-Way ANOVA to account for any variability, which may occur between each In situ experiment.

more dorsally from their normal position. The mOR256-17 positive glomerulus in Figure $4 \mathrm{H}$ is the same very large

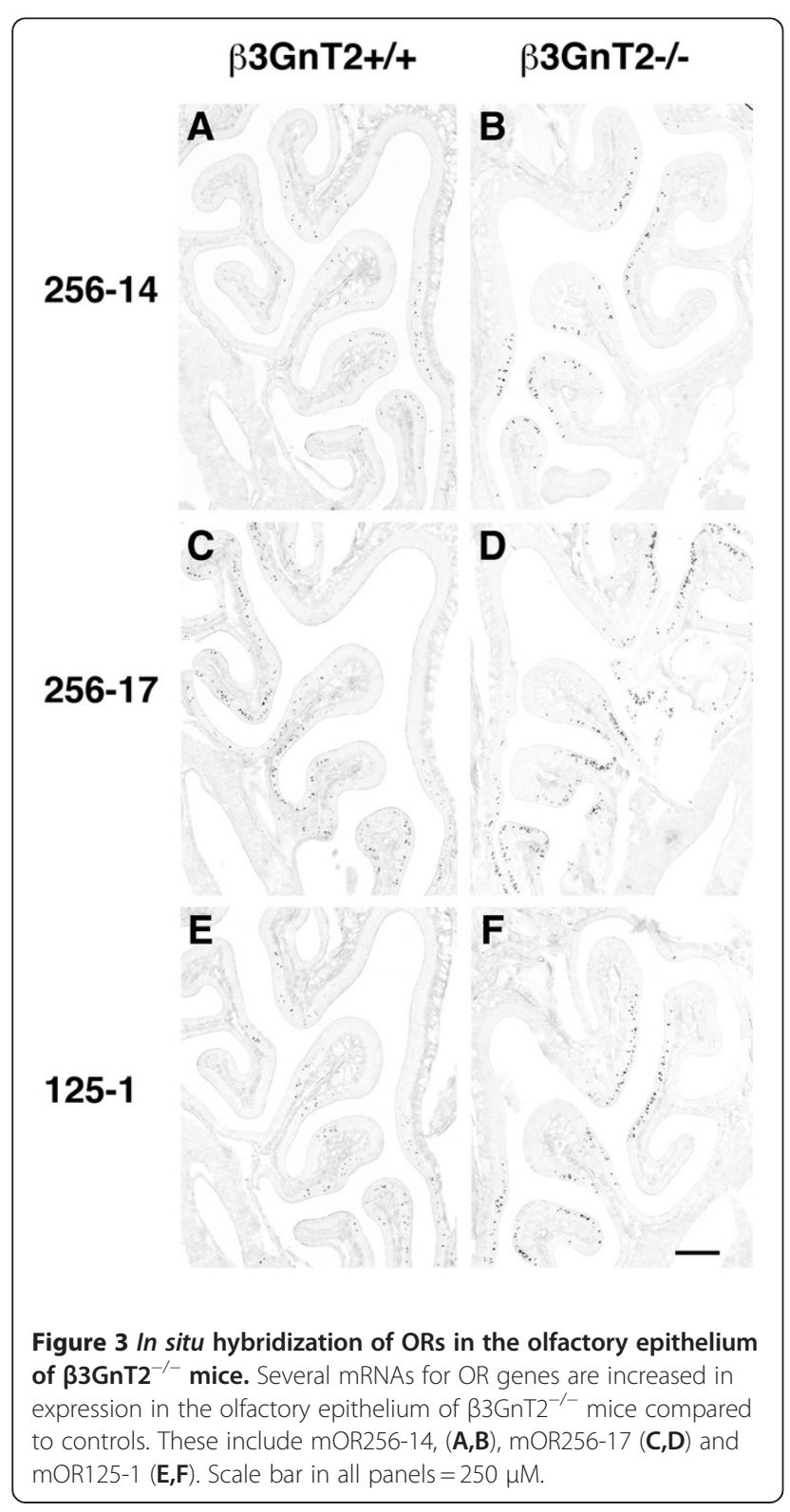

glomerulus as the more dorsal glomerulus in Figure 4G. The aberrant positions of glomeruli in null mice is very similar from mouse to mouse, just as OR-defined glomeruli are found within a very restricted area of the OB in WT mice. We previously showed that this was also the case for M72 glomeruli [9]. These results suggest that other guidance information is maintained in $\beta 3 \mathrm{GnT}^{-/-}$mice that continues to steer axons to specific but aberrant targets.

A map of the positions of mOR256-17 glomeruli in the adult OB clearly shows the difference between the WT and B3GnT2 mutant mouse. The map is a two-dimensional representation of the glomerular layer, looking down at the dorsal surface of the $\mathrm{OB}$ after it has been flattened by unrolling it from the ventral midline, rostral is at the top. The map of the mOR256- $17^{+}$glomeruli in WT OBs (green circles Figure 5A) shows two lateral glomeruli rostral to the $\mathrm{AOB}$, midway between the dorsal and ventral surfaces of the $\mathrm{OB}$ and two medial glomeruli close to the caudal end of the $\mathrm{OB}$, midway between the dorsal and ventral surfaces of the main $\mathrm{OB}$.

The map of the $\beta 3 \mathrm{GnT} 2^{-/-}$OB (Figure $5 \mathrm{~B}$ ) is smaller along the rostrocaudal axis but has similar dimensions to the WT OB along the mediolateral axis. As shown in this map, there are seven glomeruli in total (red circles in Figure 5B), compared with four glomeruli in the WT OB. Although glomeruli are not located in an absolutely fixed position from mouse to mouse, most glomeruli map to within 100 to two hundred microns of the position shown on this map. In addition, three of the mOR256-17 positive glomeruli on the lateral surface of the $\beta 3 \mathrm{GnT}^{-/-}$OBs are near the ventral surface of the $\mathrm{OB}$. On the medial surface of the mutant $\mathrm{OB}$, one of the glomeruli is positioned identically to the WT medial glomeruli, but the other two glomeruli are scattered ventrally and dorsally.

\section{Axons from under-represented $O R s$ extend into the $O B$} Although the level of expression of many ORs is significantly decreased in the OE of $\beta 3 \mathrm{GnT} 2$ mice, independent analysis using transgenic mice, in situ hybridization or immunocytochemistry reveals that expression of these ORs is 


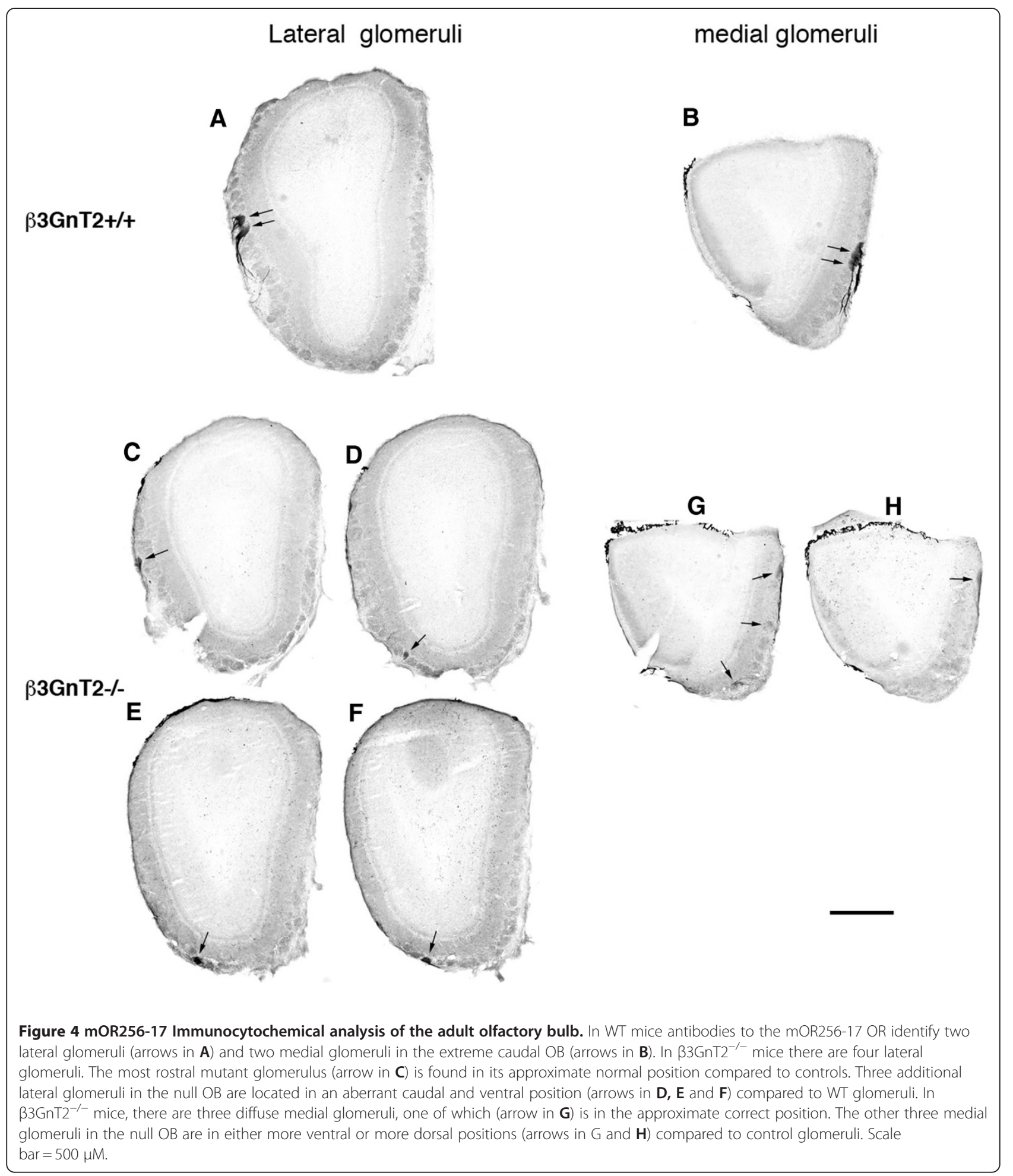

not completely lost; rather the number of OR expressing cells may be greatly reduced (Figure 1, Table 2). For example, gene array data showed that the 17 odorant receptor was decreased by more than $50 \%$ and in situ hybridization and RT-qPCR results indicated that the number of P2 neurons and $\mathrm{mOR}_{2} 8^{+}$neurons were decreased by $78 \%$ and $80 \%$ respectively in $\beta 3 \mathrm{GnT} 2^{-/-}$mice compared to controls. In order to examine the fate of axons expressing under-represented ORs in $\beta 3 \mathrm{GnT}^{-/-}$ mice, we studied two OR subsets independently, I7-GFP ${ }^{+}$ 




B $\quad \beta 3 G n T 2^{-1-}$

axons using GFP fluorescence combined with synaptophysin labeling of presynaptic terminals and $\mathrm{mOR} 28^{+}$axons by immunocytochemistry. In WT mice, the medial $\mathrm{I}^{+}$ glomerulus is normally visible near the ventral midline (arrow in Figure 6A). Although we have never seen an I7$\mathrm{GFP}^{+}$glomerulus in postnatal $\beta 3 \mathrm{GnT} 2^{-/-}$mice, $\mathrm{I7}-\mathrm{GFP}^{+}$ axons are detectable in the nerve layer and glomerular layer of adult null mice. In Figure $6 \mathrm{~B}$, an $\mathrm{I}^{+}$axon can be seen entering a synaptophysin ${ }^{+}$glomerulus (arrow) in approximately the correct location of the $\beta 3 \mathrm{GnT}^{-/-} \mathrm{OB}$. However, this glomerulus is for the most part I7 negative but synaptophysin positive, indicating that it is principally populated by axons expressing other ORs.

Gene array analysis showed that mOR28 mRNA was reduced more than any other OR and RT-qPCR results indicated that mOR2 28 mRNA was significantly decreased in $\beta 3 \mathrm{GnT} 2^{-/-}$OEs compared to wild type OEs (Figure 1). Immunocytochemical analysis (Figure 6C, D) confirms that the number of mOR $28^{+}$neurons is decreased by about $75 \%$ in $\beta 3 \mathrm{GnT} 2^{-/-}$OEs. In spite of the severe loss of mOR2 28 expression in $\beta 3 \mathrm{GnT} 2^{-/-}$mice, immunoreactive axon projections are visible in the nerve layer of the $\mathrm{OB}$ and can be seen targeting glomeruli in the same location that mOR $28^{+}$axons normally form glomeruli in WT mice (arrows in Figure 6E,F).

\section{Neuronal activity is unchanged in $\beta 3 \mathrm{GnT} 2$ null mice}

Previous studies have identified two distinct mechanisms for the regulation of OSN gene expression by olfactory signaling reviewed in [7]. One class of genes, including axon guidance cues such as Nrp1 and Sema3A, are directly modulated by cAMP levels established by AC3 $[4,13]$. For a second class of genes, transcriptional levels are determined by neuronal activity downstream of AC3. This molecular subset exhibits $\mathrm{OE}$ expression changes in either naris occluded mice or anosmic cyclic nucleotide gated channel subunit A2 (CNGA2) null mice that are not directly cAMP-dependent [5,17]. For example, microarray analysis studies revealed that RNA levels of the Leucine Rich Repeat Containing $3 \mathrm{~b}$ (Lrrc3b) gene are decreased more than tenfold in CNGA2 null OEs relative to WT mice, while those of the calcium binding protein calretinin are elevated nearly four-fold by the loss of activity.

We reasoned that $\beta 3 \mathrm{GnT} 2^{-/-}$mice should show similar gene alterations if the perturbations in olfactory connectivity and cAMP signaling compromised odor-evoked activity. Surprisingly, this was not the case (Figure 7A), as the activity-dependent genes we analyzed by in situ hybridization were unchanged in $\beta 3 \mathrm{GnT}^{-/-}$mice except for the loss of mature OSNs described previously [6]. Lrrc3b expression is unchanged in OSNs of the thinner null $\mathrm{OE}$, despite the dramatic loss of Lrrc3b evident in CNGA2 null OEs. S100A5, which is downregulated eight-fold in CNGA2 null mice, remains robustly expressed in $\beta 3$ GnT2 knockouts. Likewise, calretinin expression is unchanged in the basal layer of the $\beta 3 \mathrm{GnT}^{-/-} \mathrm{OE}$, despite the fact that its expression is significantly increased and redistributed throughout the OE of CNGA2 KOs [18].

To confirm these results (Figure 7B), we used qPCR to determine expression levels of activity-dependent genes relative to known markers for the neuron populations that undergo dynamic changes in $\beta 3 \mathrm{GnT}^{-/-}$mice. Expression levels of Lrrc3b, S100A5 and Kirrel2 decrease in parallel with those of OMP, a marker for the mature neurons that are lost in $\beta 3 \mathrm{GnT} 2^{-/-}$mice [6]. Because of the 


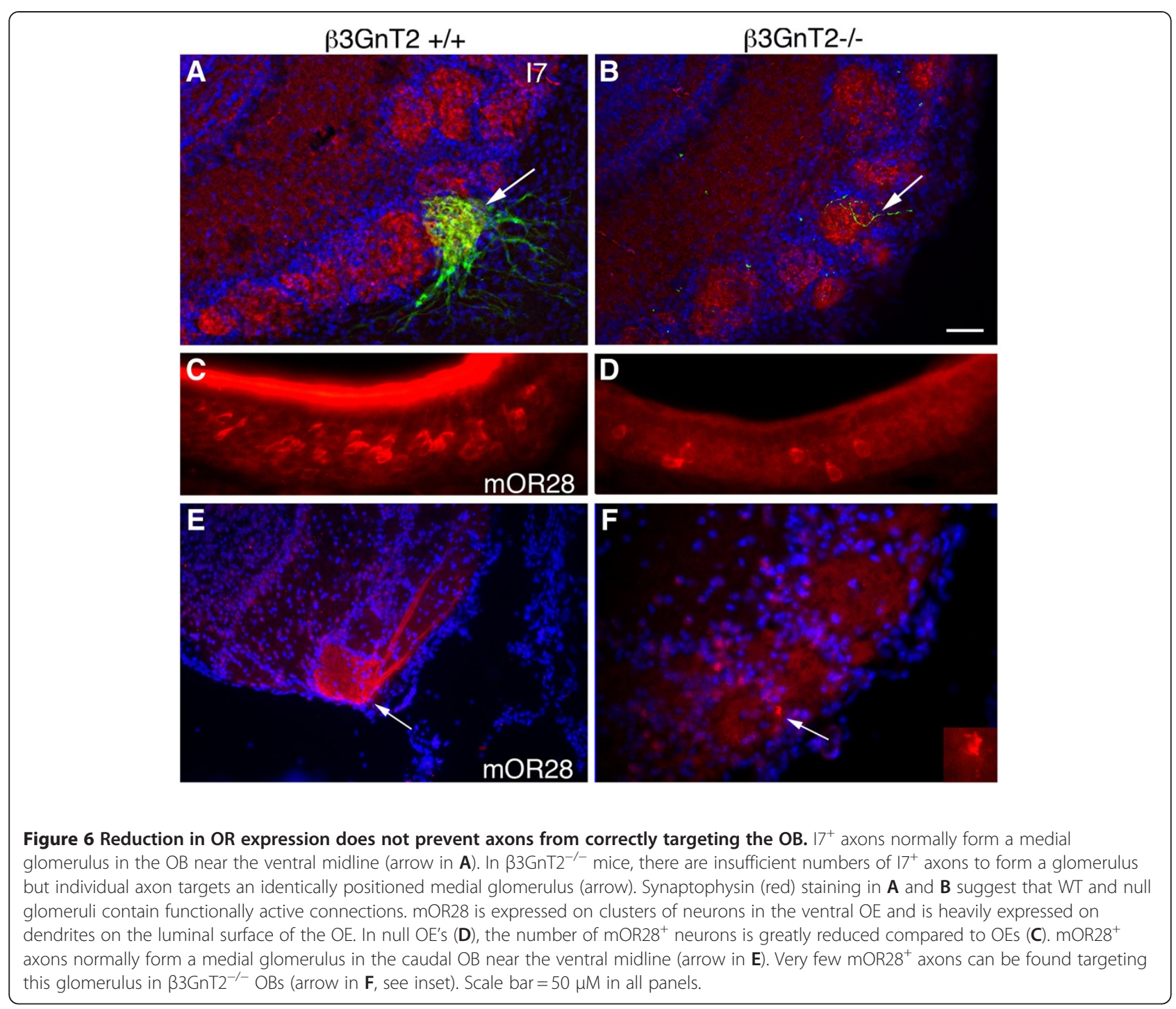

loss of mature OSNs, immature neurons expressing GAP43 increase proportionally in the $\beta 3 \mathrm{GnT}^{-/-} \mathrm{OE}[6]$. Despite this, calretinin levels are not significantly altered by the loss of $\beta 3 \mathrm{GnT} 2$, and there is no redistribution to more apical layers, as reported for CNGA2 knockout mice [18]. These results suggest that neuronal activity in the localized environment of olfactory cilia is not severely compromised in $\beta 3 \mathrm{GnT} 2^{-1-}$ mice compared with CNGA2 null mice.

\section{GnT2 null mice have minor olfactory discrimination deficits}

The significant loss of OR gene expression and the axon guidance errors, coupled with the dramatic decrease in AC3 activity reported earlier [6], we expected $\beta 3 \mathrm{GnT} 2^{-/-}$ mice to have a significant loss in olfactory discrimination ability. We, therefore, examined the performance of 9to 13 -week-old $\beta 3 \mathrm{GnT} 2^{+/+}$and $\beta 3 \mathrm{GnT}^{-/-}$mice in an olfactory discrimination task using structurally unrelated odors. In this assay, mice are trained to associate a food reward with one of two odors. Training took place over a two-day period and testing followed on Days 3 and 4. This test was designed to provide intermittent reinforcement during the first test sessions of Days 3 and 4 so that both wild type and null mice improved their discriminatory ability on Day 4 compared to Day 3 (Figure 8). An initial t-test comparison of the animals with or without a food reward, within a given day, showed no differences on either of the testing days $(P=0.24$ to 0.47$)$. Therefore, the data within each day were combined and compared using a two-way repeated measures ANOVA using genotype and day as factors (there is no significant statistical interaction between genotype and day, $P=0.77$ ).

The analysis shows that $\beta 3 \mathrm{GnT} 2^{-/-}$mice were able to discriminate all six odor pairings but that they had a significant deficit in their ability to discriminate three of the 
A



B

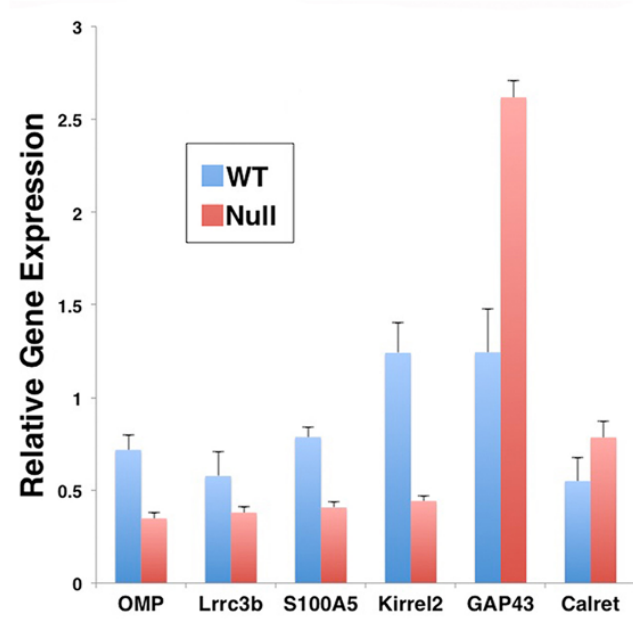

Figure $\mathbf{7}$ In situ hybridization of odor-evoked activity dependent genes in the OE. A. The expression of genes that are regulated by activity-dependent processes were analyzed in adult WT and $\beta 3 \mathrm{GnT} 2^{-/-}$OEs. Calretinin, which is expressed in immature neurons and is greatly enriched in $\mathrm{CNGA}^{-/-}$mice is unchanged in expression in $33 \mathrm{GnT}^{-/-}$OEs. The Leucine Rich Repeat Containing (Lccr3b), S100A5, and kirrel2 genes, which are all expressed in mature neurons in WT OEs and down-regulated in CNGA2 $2^{-1}$ mice, are also unchanged in levels of mRNA expression. Note that increased cell death in $\beta 3 \mathrm{GnT}^{-/-}$OEs results in a thinner layer of mature neurons [8]. Scale bar $=50 \mu \mathrm{M}$ in all panels. $\mathbf{B}$. Real-time quantitative PCR analysis of activity-dependent gene expression in microdissected adult wild type and $\beta 3 \mathrm{GnT} 2^{-/-} \mathrm{OE}$ samples. Relative levels of Lrrc3b, S100A5 and kirrel2 mRNA in null mice decreases in parallel with the mature neuron marker OMP. Immature neurons expressing GAP-43 correspondingly increase in proportion in the null OE. Consistent with this, calretinin expression in the basal OE is preserved in null mice. Thus, the expression of activity-dependent genes fluctuates only in accordance with the dynamics of the cell population they are expressed in, suggesting that odor-evoked activity is not as severely compromised in $\beta 3 \mathrm{GnT}^{-/-}$mice relative to CNGA2 mutants. Error bars are the mean $+/-$ SEM ( $n=3$ for GAP- $43 ; n=6$ for all others).

six odor pairings either on Day 3 or Day 4 compared to littermate controls (asterisks in Figure 8). On Day 4, null mice showed a deficit to two of the six odors, citronellal and decanal, both 10 carbon aldehydes but with several structural differences. Decanal was the only odor to which $\beta 3 \mathrm{GnT}^{-/-}$mice consistently displayed a deficit on both Days 3 and 4. Had the null mice been tested for their ability to discriminate between enantiomers or mixtures of enantiomers, it is likely that further deficits would have been revealed.

\section{Discussion}

Olfactory perception critically depends on the formation of a functional olfactory map in which neurons expressing a given receptor converge on conserved locations in the olfactory bulb. We have previously shown that mice lacking $\beta 3$ GnT2 display abnormal olfactory system development. These mice have significant errors in the guidance of sensory axons to proper targets in the $\mathrm{OB}$ [8]. In WT mice AC3 is directly glycosylated by $\beta 3 \mathrm{GnT} 2$ but in knockout mice this form of polylactosamine (PLN) glycosylation is absent and AC3 enzymatic activity is decreased by 80 to $90 \%$ [6]. In order to better understand the role of PLN-glycosylation in olfactory development, we have analyzed the expression of ORs in $\beta 3 \mathrm{GnT}^{-/-}$mice and further examined guidance of specific axon subsets. Results presented here show that in spite of depleted cAMP levels, significant decreases in expression of many ORs, and the presence of many wiring errors, $\beta 3 \mathrm{GnT} 2^{-/-}$mice have a surprising ability to discriminate odors. These results are in agreement with previous studies suggesting that mutations that alter the organization of the olfactory system may have relatively minor effects on associative behaviors such as olfactory discrimination [19]. The odor-specific patterns of neural activity generated in the $\mathrm{OBs}$ of $\beta 3 \mathrm{GnT}^{-/-}$mice are likely to be significantly different from WT controls in many instances, due to changes in OR expression and alterations in glomerular targeting. Although these anatomical perturbations are likely to contribute to the differences observed in our behavioral testing paradigm, the fact that odor discrimination in mutant mice is largely intact suggests that odor-specific patterns of neuronal activity need not be the same in individual animals for them to discriminate odors with significant structural diversity.

Expression of many ORs is reduced in $\beta 3 \mathrm{GnT}^{-/-}$mice In this current study, profiling global gene expression in OSNs using microarrays revealed that many other ORs 


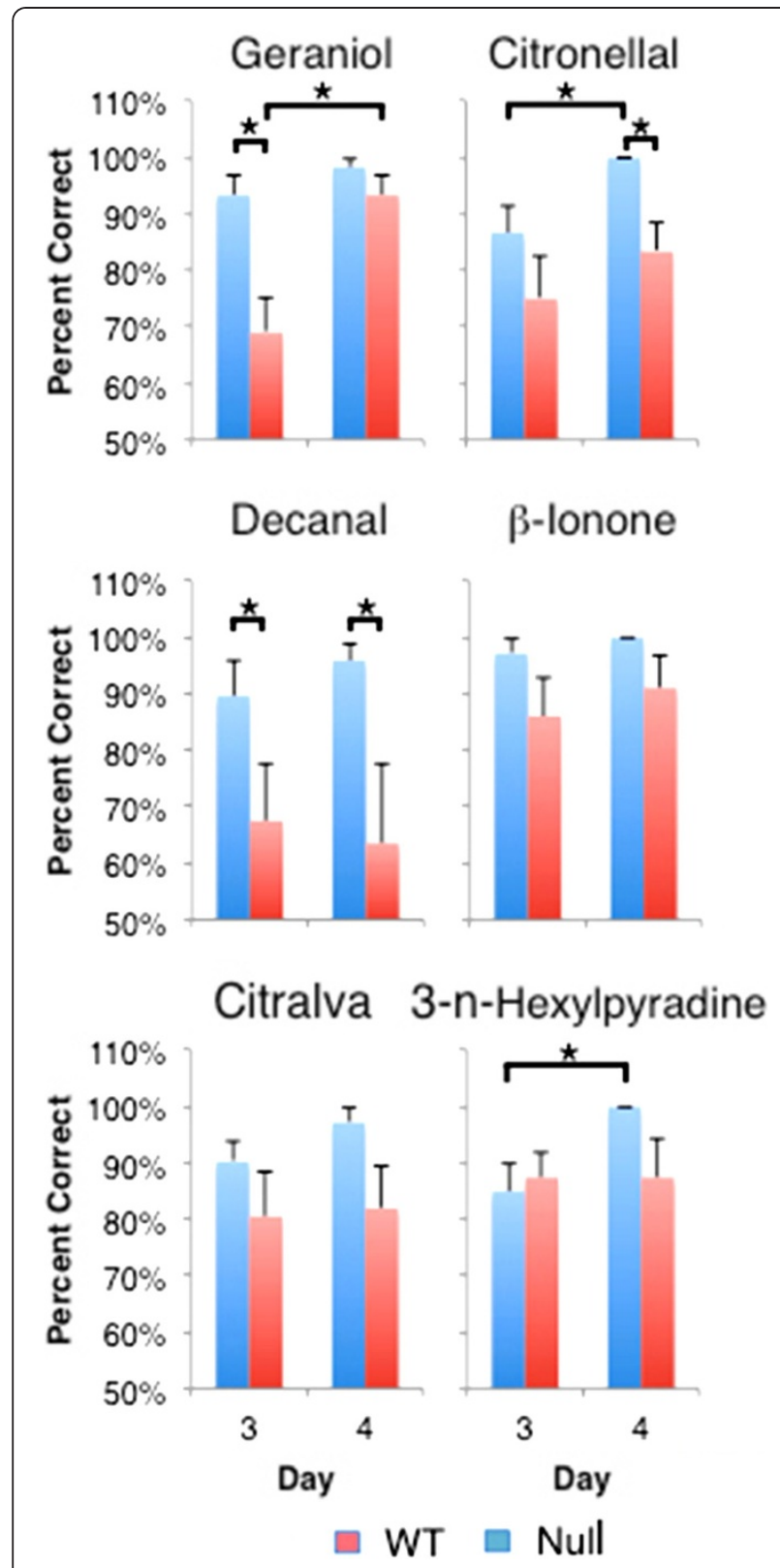

Figure $8 \beta 3 \mathrm{GnT}^{-/-}$mice retain the majority of their olfactory discriminatory ability. Mice were tested against pairs of odors for their ability to associate odor with a food reward. $\beta 3 \mathrm{GnT}^{-1}$ mice can discriminate two of the odors, citralva and $\beta$-ionone as well as wild type controls. There is a significant (asterisks) reduction in the ability of null mice to discriminate geraniol, citronellal, decanal, and 3-n-hexylpyridine, but the differences are small and highly variable.

were likely to be misregulated in the $\beta 3 \mathrm{GnT}^{-/-} \mathrm{OE}$. Following up on these findings with detailed RT-qPCR analyses, we identified three ORs that were significantly increased in expression in $\beta 3 \mathrm{GnT}^{-/-}$mice and three that were significantly decreased in expression. In order to determine whether these changes were the result of changes in expression levels or of differences in cell number, we performed in situ hybridization studies of six ORs also varying in chromosomal location, and $\mathrm{OE}$ zone. The results indicate that mRNA levels for each OR analyzed correlate closely with the number of OR-expressing OSNs that are maintained, suggesting that OR transcriptional levels per neuron are relatively steady. One possible explanation for the changes in expression of these various neuronal populations is that less active neurons may be lost due to competition with more active neurons. Although odor-evoked activity plays a limited role in establishment of the olfactory map, decreased sensory activity can increase the number of heterogeneous glomeruli [20] and activity-dependent competition may contribute to segregation of axons and refinement of connections in the $\mathrm{OB}$ [21]. Another possibility is that switching may occur from one OR gene to another $[22,23]$, although we have no evidence that this takes place more frequently in $\beta 3 \mathrm{GnT} 2^{-1-}$ mice than in controls. When an OR gene is deleted, affected OSNs compensate by expressing a different OR, although the replacement receptor would have different binding characteristics [24]. Thus, competition may favor neurons that receive greatest stimulation from a limited repertoire of odorants in their environment.

\section{Olfactory discrimination is reduced in $\beta 3 \mathrm{GnT}^{-/-}$mice}

Although a direct relationship between correct axon targeting and olfactory discrimination has not been established, several studies have shed considerable light on this issue. On the one hand, rats retained most of their olfactory discrimination following surgical removal of significant portions of the target [25]. In contrast, accurate axon targeting in the DII region of the OB appeared to be required for responsiveness to aversive cues [26]. Several other strains of transgenic mice with reduced OR expression or neuronal activity have been tested for their ability to discriminate odors. Using a water reward method to distinguish paired odors, M71 transgenic mice, which under-express many ORs, were able to discriminate between structurally unrelated odors and even between enantiomers but were unable to distinguish mixtures of enantiomers [19]. However, it is not clear how much discriminatory ability is conferred by the over-represented OR, M71, as opposed to the underexpressed ORs [19]. Similarly, although AC3 knockout mice are completely anosmic, AC3 heterozygous mice were shown to have a significant olfactory discrimination deficit [14]. Using either an olfactory avoidance method or a food reward-based test, they showed that AC3 heterozygous mice could discriminate lilial and citralva approximately $50 \%$ as well as WT mice, commensurate with a $50 \%$ reduction in the levels of $\mathrm{AC} 3 . \beta 3 \mathrm{GnT} 2^{-/-}$ 
mice express only 10 to $20 \%$ of the WT levels of AC3, have reduced levels of OR expression and also axon guidance defects as shown here and previously documented $[6,8]$. We, therefore, tested $\beta 3 \mathrm{GnT} 2^{-/-}$mice for their ability to discriminate odors using the same foodbased reward paradigm that revealed a deficit in AC3 heterozygous mice. Due to the severe nature of the anatomical, biochemical and signaling deficits seen in $\beta 3 \mathrm{GnT}^{-/-}$mice, we tested odors that were structurally dissimilar (although geraniol, citralva and citronellal have some common features) but had similar adenylyl cyclase stimulatory capabilities. Furthermore, some of the odors tested were ones that had previously been tested in AC3 transgenic mice. For example, AC3 heterozygous mice display a gene-dose dependent decrease in ability to discriminate citralva [14], suggesting that olfactory discriminatory ability is directly related to the levels of AC3 protein in cilia. In contrast, discrimination of citralva by $\beta 3 \mathrm{GnT}^{-/-}$mice was not statistically different from WT mice. Although AC3 is decreased on olfactory axons in $\beta 3 \mathrm{GnT} 2^{-/-}$mice, the levels of AC3 protein in residual OSN cell bodies and cilia is relatively normal [6], suggesting that signaling required for neuronal activity is largely maintained in null OSN cilia.

\section{Additional examples of axon guidance errors in $\mathrm{B3GnT2}^{-/-}$mice}

We show here, in addition to the changes in OR expression, further examples of aberrant axon guidance in $\beta 3 \mathrm{GnT} 2^{-/-}$ mice. Using immunocytochemical techniques, we showed that mOR256-17 $7^{+}$axons are mistargeted to multiple glomeruli on the medial and lateral surfaces of the OB. However, some mOR256-17 $7^{+}$axons form a small glomerulus very close to where their normal target should be located. Furthermore, even though only a few $\mathrm{I}^{+}$and $\mathrm{mOR} 28^{+}$axons innervate glomeruli in the adult $\mathrm{OB}$, these axons never reach the level required to form their own unique pair of glomeruli. It is possible that just a small number of OR-specific axons connecting to mitral or tufted cells in the correct targeting region of the OB is sufficient to transduce a signal that is correctly interpreted in the olfactory cortex. These results suggest that although a smaller number of neurons expressing a given OR will likely decrease the probability that an odorant-binding event will lead to perception of that odor, only a small number of connections may actually be required for successful transduction [27].

\section{Odor-evoked activity is maintained in $\beta 3 \mathrm{GnT}^{-/-}$mice}

Olfactory axon guidance is orchestrated via a signaling cascade that includes $\mathrm{G}$ protein-coupled receptors, AC3 activation, cAMP synthesis and a downstream pathway involving PKA and CREB [4,28-30]. Thus, activation of $\mathrm{AC} 3$ is the key regulator of signaling pathways that subsequently control expression of a number of axon guidance and adhesion molecules, including ephrins, kirrels, neuropilin-1, Sema3A and BIG2 [6,29,31,32]. Importantly though, we show here that odor-evoked activity dependent gene transcription is unaffected in $\beta 3 \mathrm{GnT} 2^{-/-}$OEs, further supporting the possibility that AC3 activity is preferentially preserved in cilia of these null mice. Interestingly, in many CNS neurons and glia where $\beta 3 \mathrm{GnT2}$ is not expressed, AC3 expression is restricted to primary cilia [33]. AC3 is one of several proteins that are actively transported into cilia by a family of proteins associated with renal cystic disease, MKS1 and 3 [34]. Tectonic1, a member of a family of signalsequence-containing proteins that forms a membrane complex with MKS and other proteins, is required for the ciliary localization of AC3 [35]. OSNs appear to express AC3 differently than CNS neurons and most other cells. Although AC3 is heavily concentrated in WT olfactory cilia, it is also expressed in cell soma and on axons $[6,12]$. In the absence of PLN-glycosylation, AC3 expression on axons is greatly reduced, although the normal levels of AC3 detected in OSN cells bodies and cilia in $\beta 3 \mathrm{GnT} 2^{-/-}$OEs suggest that the remaining AC3 may preferentially localize to cilia [6]. This would support a hypothesis that a role for $\beta 3 \mathrm{GnT} 2$ is to ensure that a significant percentage of AC3 protein is not transported to cilia in OSNs, rather than PLN on AC3 and other surface glycoproteins is responsible for maintaining their axonal expression. In fact, all of the components of this canonical transduction process are expressed in axons and it has been suggested that local cAMP synthesis could control expression of guidance proteins specifically in axons [36].

\section{Conclusions}

Olfactory discrimination testing shows that $\beta 3 \mathrm{GnT} 2^{-/-}$ mice have a modest deficit in their ability to distinguish odors. This is in spite of the fact that hundreds of ORs are underrepresented in the $\mathrm{OE}$ and many probably do not innervate normal glomeruli in the OB. Furthermore, axon guidance in $\beta 3 \mathrm{GnT}^{-/-}$mice is aberrant, as shown by the abnormal position and increased number of mOR256-17 $7^{+}$glomeruli in the OB of knockout mice. Moreover, we have previously shown that AC3 activity is decreased by 80 to $90 \%$ in $\beta 3 \mathrm{GnT} 2^{-/-}$mice, such that guidance and adhesion molecules such as neuropilin-1 and kirrel 2 are poorly expressed in axons [6].

The $\beta 3 \mathrm{GnT}^{-/-}$mouse is a unique model of reduced cAMP production in which most of the residual AC3 activity appears to be concentrated in cilia where odorevoked transduction is largely intact. In contrast, cAMPdependent transcriptional regulation required for proper axon guidance is virtually absent. An important question that remains unanswered is to what degree glomerular 
heterogeneity can be tolerated before olfactory discrimination is significantly compromised. Results presented here would suggest that the mouse olfactory system may have a large capacity to withstand down regulation of cAMP signaling, significant deletions in the OR repertoire, alterations in guidance molecule expression and errors in wiring before suffering significant losses of olfactory perception.

\section{Methods}

Animals

Wild type and $\beta 3 \mathrm{GnT} 2^{-/-}$mouse littermates were generated from $\beta 3 G n T 2$ het/het crosses. PCR was used to genotype the offspring, with a 700-bp fragment amplified from the wildtype $\beta 3 \mathrm{GnT} 2$ allele and a 1,071-bp fragment amplified from the $\beta 3 \mathrm{GnT} 2^{-/-}$allele. $\beta 3 \mathrm{GnT}^{-/-}$mice were established from the KST308 embryonic stem cell line, which harbors a secretory trap vector insertion in the $\beta 3 \mathrm{GnT} 2$ coding sequence as previously described $[8,37]$. Mice were housed according to standard National Institutes of Health and institutional care guidelines, and procedures were approved by the University of Massachusetts Medical School Institutional Animal Care and Use Committee (Worcester, MA, USA).

\section{In situ hybridization}

Digoxigenin (DIG)-labeled sense and antisense riboprobes were transcribed from cDNAs containing subcloned OR coding sequences using vector-specific RNA polymerases and DIG labeling mix (Roche Molecular Biochemicals, Pleasanton, CA, USA). For in situ analysis of adult mouse OEs, age P28 mice were deeply anesthetized and transcardially perfused with $4 \%$ Formaldehyde in $0.1 \mathrm{M}$ phosphate buffer ( $\mathrm{pH}$ 7.4). Brains were removed and further fixed overnight in $4 \%$ Formaldehyde at $4{ }^{\circ} \mathrm{C}$ followed by immersion in 30\% sucrose. Bone thickness in the posterior region of the snout from the orbital area to the $\mathrm{OB}$ was reduced using surgical knives. The dissected samples were frozen on dry ice, coronally sectioned at $20-\mu \mathrm{M}$ thickness with a cryostat, and then mounted on Superfrost plus microscope slides, (Thermo Fisher Scientific, Waltham, MA USA). After prehybridization and hybridization, the DIG-labeled RNA hybrids were detected with an anti-DIG Fab fragment conjugated to alkaline phosphatase (Roche Molecular Biochemicals) at a dilution of 1:1,000 overnight at $4^{\circ} \mathrm{C}$. The color reaction was produced with nitro blue tetrazolium chloride and 5-bromo-4-chloro-3-indolyl phosphate with levamisole added to block endogenous phosphatase activity.

\section{Histology and Immunocytochemistry}

Tissue was prepared by transcardial perfusion using $2 \%$ PLP (paraformaldehyde-lysine-periodate) fixation in $0.1 \mathrm{M}$ phosphate buffer (PB), pH 7.4. Antibodies to mOR256-17 are sensitive to fixation conditions and we determined empirically that immunoreactivity on frozen tissue sections was enhanced using 2\% PLP compared to $4 \%$ paraformaldehyde or other stronger fixatives. Heads were subsequently removed and postfixed $16 \mathrm{hrs}$ in the same fixative solution, followed by cryoprotection in 30\% sucrose. After embedding, tissue sections were prepared on a Microm HM505E cryostat at $50 \mu \mathrm{M}$ thickness and were then immediately thawed in transwell boats filled with PBS for staining as free floating sections. Tissues were blocked for one hour in $2 \% \mathrm{BSA}$, then incubated overnight at $4^{\circ} \mathrm{C}$ with the primary antibody for mOR156-17 [16] or mOR28 [38] and diluted in 1\% BSA/ PBS/0.3\% Triton X-100. After washing, tissue sections were further incubated for two hours at room temperature with species-specific secondary biotinylated antibody and visualized with the Vectastain $A B C$ peroxidase kit and 3,3'-diaminobenzadine tetrahydrochloride (Vector Laboratories, Burlingame, CA USA), or with Cy3-conjugated (Jackson Immunoresearch, West Grove, PA USA) or Alexa Fluor 488 (Invitrogen, Grand Island, NY USA) conjugated secondary antibodies. Images were captured using a Zeiss Axioplan photomicroscope equipped with a Spot RT camera (Diagnostic Instruments (Sterling Heights MI USA).

\section{Cell counts}

Specific OR-expressing neurons in PD28 OEs of $\beta 3 \mathrm{GnT} 2^{-/-}$ and WT control mice were quantified using a Nikon Eclipse E400 microscope (MVI, Inc., Avon MA USA) at 100X. The complete OE cavity was serial sectioned at $20 \mu \mathrm{M}$ and collected on 20 to 22 slides per case. Each in situ hybridization experiment included a pair of $\beta 3 \mathrm{GnT}^{-/-}$and WT slides for each OR probe. Each probe was used on three different pairs of mice. All the sections from one slide of each genotype were counted and used for analysis. These counts were compared using a paired two-way ANOVA to control for any variability, which may occur between each in situ experiment. In addition, pairs of slides within a case, using one probe, were counted and compared and found to be less than 3\% different, which was not significant (NS). Thus, we extrapolated the total amount of labeled cells for each OR by adjusting the counts to the total number of slides in each case (Table 2). Statistical analysis was performed using SigmaStat 2.0 (Systat software, San Jose, CA USA).

\section{Real time reverse transcriptase quantitative PCR}

RNA was extracted from microdissected olfactory epithelia of $6 \mathrm{BGnT2}^{+/+}$and $\beta 3 \mathrm{GnT}^{-/-}$mice at six months of age using Trizol Reagent (Invitrogen), and cDNA prepared as described previously (Henion et al., 2011). Quantitative PCR (qPCR) was performed with oligonucleotides designed using online Primer3 software (version 0.4.0). Primer sequences used for template amplification are available upon request. Samples were amplified in 
triplicate using GoTaq Polymerase (Promega, Fitchburg, WI, USA) in a StepOnePlus Real-Time PCR System (Applied Biosystems, Life Technologies, Grand Island, NY, USA). Relative gene expression levels were determined by the Comparative $\mathrm{C}_{\mathrm{T}}$ (threshold cycle) method after normalization to RNA polymerase 2 as an endogenous reference.

\section{Gene array hybridization}

OEs from adult mice were collected in PBS on ice. Tissue samples were homogenized using TRIzol (Invitrogen, Carlsbad, CA, USA) and the RNA was collected in the aqueous phase after chloroform extraction. Subsequently, Isopropyl Alcohol was used to precipitate the RNA, followed by washing with $75 \%$ ethanol, air-dried, and redissolved in RNAse-free DEPC H2O. After this RNA isolation, a Qiagen RNeasy mini kit (Qiagen, Valencia, CA, USA) was used to further purify the RNA, and the yield analyzed with a DU 650 Spectrophotometer (Beckman Coulter Inc, Brea, CA, USA). Yields per mouse OE measured at an absorbance of $260 \mathrm{~nm}$ were 10 to $20 \mathrm{ug}$ RNA.

Affymetrix gene array technology was used to compare the gene profiles between $\beta 3 \mathrm{GnT} 2 \mathrm{WT}$ and mutant mouse strains. Individual samples were hybridized to 12 gene chips in a high-density oligonucleotide array (Affymetrix Mouse Gene 1.0 ST Array, 28,853 mouse genes (1,100 OR genes)/chip) that uses 25-mer probes distributed across the transcribed regions of each gene, with a median of 26 probes per gene. The Ambion WT Expression kit (Applied Biosystems, Foster City, CA, USA) was used to synthesize first and second strand CDNA, and generate the purified sense strand for the Affymetrix gene chip WT Terminal labeling kit (Affymetrix, Santa Clara, CA, USA). The single stranded cDNA produced by the Ambion kit was fragmented and labeled using the GeneChip WT Terminal Labeling Kit. The product was then hybridized to the chip for 16 to 17 hours at $45^{\circ} \mathrm{C}$, washed, stained and scanned using the Affymetrix GeneChip Array Scanner. The log based signal values were generated using the RMA algorithm in Expression Console. For each pair of samples, results of each probe were compared and an " $R$ " value was calculated. The median of the " $R$ " values of each probe set (R_median) was used for filtering the potentially differential gene expression. No normalization was conducted.

\section{Olfactory discrimination task}

$\beta 3 \mathrm{GnT}^{+/+}$and $\beta 3 \mathrm{GnT}^{-/-}$mice 9 to 13 weeks old were trained in an olfactory discrimination task [39]. Pairs of odors, each known to elicit strong cAMP responses were used in the sand buried food task to measure an animal's ability to associate an odor with a reward [40]. The mice were food-deprived for 24 hours before the first day of testing began then maintained on a restricted diet throughout the four day trial. On Day 1, the mice were allowed to locate a food reward in the sand. Day 2 was a training day in which each mouse was presented with a food reward in the sand, which was associated with a test odor. The test odors were shifted to different positions within the cage during the training and subsequent testing days. The training period consisted of six 20-minute time periods with 10-minute intervals, where each mouse would have an opportunity to locate the food reward. Early in the training the mice were allowed additional time, if necessary, to locate the food reward. On Day 3, mice were given a choice between a novel odor and the same test odor presented on Day 2. Subsequent sets of six trials each on Days 3 and 4 were scored either correct or incorrect accordingly to which dish each mouse would begin digging. Days 3 and 4 consisted of two separate sets of trials. In the first set of trials the mice were tested without a buried food reward, while in the second set of trials the reward was present.

\section{Abbreviations}

AC3: Adenylyl cyclase 3; CNG: Cyclic nucleotide gated channel; CREB: Cyclic nucleotide response element binding protein; DIG: Digoxigenin; OB: Olfactory bulb; OE: Olfactory epithelium; OR: Odorant receptor OSN, olfactory sensory neuron; Nrp1: Neuropilin-1; PBS: Phosphate-buffered saline; PKA: Protein kinase A; PLN: Polylactosamine; RT-qPCR: Reverse transcriptase quantitative polymerase chain reaction; Sema3A: Semaphoring $3 A$; WT: Wild type.

\section{Competing interests}

The authors declare that they have no competing interests.

\section{Acknowledgements}

This work was supported by the National Institutes of Health Grant DC00953. We are grateful to Gilad Barnea, Brown University for the generous gift of mOR28 antibodies, to Phyllis Spatrick, UMass Genomics Core Facility for carrying out the Affymetrix GeneChip hybridization experiments.

\section{Author details}

${ }^{1}$ Cell Biology Department, University of Massachusetts Medical School, 55 Lake Avenue North, Worcester, MA 01655, USA. ${ }^{2}$ Academic Research Computing, University of Massachusetts Medical School, Worcester, MA01655, USA. ${ }^{3}$ Institute of Physiology, University of Hohenheim, 70593, Stuttgart, Germany.

\section{Authors' contributions}

TKK designed most of the experiments and drafted the initial manuscript. PAM and AAF performed the gene array and RT-qPCR experiments. MX analyzed the gene array data. JS provided the 256-17 antibody and helped to revise the manuscript. TRH supervised the molecular analyses and helped to write and revise the manuscript. GAS supervised the whole study and edited the manuscript. All authors read and approved the final manuscript.

Received: 5 December 2011 Accepted: 4 May 2012

Published: 4 May 2012

\section{References}

1. Mombaerts P, Wang F, Dulac C, Chao SK, Nemes A, Mendelsohn M, Edmondson J: Visualizing an olfactory sensory map. Cell 1996, 87:675-686.

2. Vassar R, Chao SK, Sitcheran R, Nuñez JM, Vosshall LB, Axel R: Topographic organization of sensory projections to the olfactory bulb. Cell 1994, 79:981-991.

3. Wang F, Nemes A, Mendelsohn M, Axel R: ORs govern the formation of a precise topographic map. Cell 1998, 93:47-60.

4. Imai T, Suzuki M, Sakano H: Odorant receptor-derived cAMP signals direct axonal targeting. Science 2006, 314:657-661. 
5. Serizawa S, Miyamichi K, Takeuchi H, Yamagishi Y, Suzuki M, Sakano H: A neuronal identity code for the odorant receptor-specific and activity-dependent axon sorting. Cell 2006, 127:1057-1069.

6. Henion TR, Faden AA, Knott TK, Schwarting GA: $\beta 3$ GnT2 maintains adenylyl cyclase-3 signaling and axon guidance molecule expression in the olfactory epithelium. J Neurosci 2011, 31:6576-6586.

7. Imai T, Sakano H: Odorant receptor-mediated signaling in the mouse. Curr Opin Neurobiol 2008, 18:251-260.

8. Henion TR, Raitcheva D, Grosholz R, Biellmann F, Skarnes WC, Hennet T, Schwarting GA: Beta1-3-N-Acetylglucosaminytransferase 1 glycosylation is required for axon pathfinding by olfactory sensory neurons. J Neurosci 2005, 25:1894-1903.

9. Schwarting GA, Henion TR: Lactosamine differentially affects olfactory sensory neuron projections to the olfactory bulb. Dev Neurobio/ 2007, 67:1627-1640

10. Trinh K, Storm DR: Vomeronasal organ detects odorants in absence of signaling through main olfactory epithelium. Nat Neurosci 2003, 6:519-525.

11. Chesler AT, Zou DJ, Le Pichon CE, Peterlin ZA, Matthews GA, Pei X, Miller $M C$, Firestein S: A G protein/cAMP signal cascade is required for axonal convergence into olfactory glomeruli. Proc Natl Acad Sci USA 2007, 104:1039-1044.

12. Col JA, Matsuo T, Storm DR, Rodriguez I: Adenylyl cyclase-dependent axonal targeting in the olfactory system. Development 2007, 134:2481-2489.

13. Imai T, Yamazaki T, Kobayakawa R, Kobayakawa K, Abe T, Suzuki M, Sakano $\mathrm{H}$ : Pre-target axon sorting establishes the neural map topography. Science 2009, 325:585-590.

14. Wong ST, Trinh K, Hacker B, Chan GC, Lowe G, Gaggar A, Xia Z, Gold GH, Storm DR: Disruption of the type III adenylyl cyclase gene leads to peripheral and behavioral anosmia in transgenic mice. Neuron 2000, 27:487-497.

15. Iwema CL, Fang H, Kurtz DB, Youngentob SL, Schwob JE: Odorant receptor expression patterns are restored in lesion-recovered rat olfactory epithelium. J Neurosci 2004, 14:356-369.

16. Strotmann J, Levai O, Fleischer J, Schwartzenbacher K, Breer H: Olfactory receptor proteins in axonal processes of chemosensory neurons. J Neurosci 2004, 24:7754-7761.

17. Oztokatli H, Hornberg M, Berghard A, Bohm S: Retinoic acid receptor and CNGA2 channel signaling are part of a regulatory feedback loop controlling axonal convergence and survival of olfactory sensory neurons. FASEB J 2012, 26:617-627.

18. Bennett MK, Kulaga HM, Reed RR: Odor-evoked gene regulation and visualization in olfactory receptor neurons. Mol Cell Neurosci 2010, 43:353-362.

19. Fleischmann A, Shykind BM, Sosulski DL, Franks KM, Glinka ME, Mei DF, Sun Y, Kirkland J, Mendelsohn M, Albers MW, Axel R: Mice with a "monoclonal nose": perturbations in an olfactory map impair odor discrimination. Neuron 2008, 60:1068-1081.

20. Zou DJ, Feinstein P, Rivers AL, Mathews GA, Kim A, Greer CA, Mombaerts $P$ Firestein S: Postnatal refinement of peripheral olfactory projections. Science 2004, 304:1976-1979.

21. Zhao H, Reed RR: X inactivation of the OCNC1 channel gene reveals a role for activity-dependent competition in the olfactory system. Cell 2001, 104:651-660.

22. Serizawa S, Miyamichi K, Nakatani H, Suzuki M, Saito M, Yoshihara Y, Sakano $\mathrm{H}$ : Negative feedback regulation ensures the one receptor-one olfactory neuron rule in mouse. Science 2003, 302:2088-2094.

23. Lewcock JW, Reed RR: A feedback mechanism regulates monoallelic odorant receptor expression. Proc Natl Acad Sci U S A 2004, 101:1069-1074.

24. Shykind BM, Rohani SC, O'Donnell S, Nemes A, Mendelsohn M, Sun Y, Axel R, Barnea G: Gene switching and the stability of odorant receptor gene choice. Cell 2004, 117:801-815.

25. Lu X-CM, Slotnick BM: Olfaction in rats with extensive lesions of the olfactory bulb: Implications for odor coding. Neuroscience 1998, 84:849-866.

26. Cho JH, Prince JE, Cutforth T, Cloutier JF: The pattern of glomerular map formation defines responsiveness to aversive odorants in mice. J Neurosci 2011, 31:7920-7926.

27. Ben-Chaim Y, Cheng MM, Yau K-Y: Unitary response of mouse olfactory receptor neurons. Proc Natl Acad Sci USA 2011, 108:822-827.

28. Watt WC, Storm DR: Odorants stimulate the ERK/mitogen-activated protein kinase pathway and activate CAMP-response element-mediated transcription in olfactory sensory neurons. J Biol Chem 2001, 276:2047-2052.

29. Sakano $\mathrm{H}$ : Neural map formation in the mouse olfactory system. Neuron 2010, 67:530-542
30. Schwarting GA, Henion TR: Regulation and function of axon guidance and adhesion molecules during olfactory map formation. J Cell Biochem 2011, 112:2663-2671.

31. Bakalyar HA, Reed RR: Identification of a specialized adenylyl cyclase that may mediate odorant detection. Science 2000, 250:1403-1406.

32. Kaneko-Goto T, Yoshihara S, Miyazaki H, Yoshihara Y: BIG-2 mediates olfactory axon convergence to target glomeruli. Neuron 2008, 57:834-846.

33. Bishop GA, Berbari NF, Lewis J, Mykytyn K: Type III adenylyl cyclase localizes to primary cilia throughout the adult mouse brain. J Comp Neurol 2007, 505:562-571.

34. Pluznick JL, Rodriguez-Gil DJ, Hull M, Mistry K, Gattone V, Johnson CA, Weatherbee S, Greer CA, Caplan MJ: Renal cystic disease proteins play critical roles in the organization of the olfactory epithelium. PLoS One 2001, 6:e19694.

35. Garcia-Gonzalo FR, Corbit KC, Sirerol-Piquer MS, Ramaswami G, Otto EA, Noriega TR, Seol AD, Robinson JF, Bennett CL, Josifova DJ, García-Verdugo $J M$, Katsanis N, Hildebrandt F, Reiter JF: A transition zone complex regulates mammalian ciliogenesis and ciliary membrane composition. Nat Genet 2011, 43:776-784.

36. Maritan M, Monaco G, Zamparo I, Zaccolo M, Pozzan T, Lodovichi C: Odorant receptors at the growth cone are coupled to localized CAMP and Ca2+ increases. Proc Natl Acad Sci USA 2009, 106:3537-3542.

37. Mitchell KJ, Pinson Kl, Kelly OG, Brennan J, Zupicich J, Scherz P, Leighton PA, Goodrich LV, Lu X, Avery BJ, Tate P, Dill K, Pangilinan E, Wakenight P, Tessier-Lavigne M, Skarnes WC: Functional analysis of secreted and transmembrane proteins critical to mouse development. Nat Genet 2001 28:241-249.

38. Barnea G, O'Donnell S, Mancia F, Sun X, Nemes A, Mendelsohn M, Axel R: Odorant receptors on axon termini in the brain. Science 2004, 304:1468.

39. Smith DR, Striplin AM, Geller RB, Mailman JD, Lawler CP, Gallagher M: Behavioral assessment of mice lacking D1A dopamine receptors. Neuroscience 1998, 85:135-146.

40. Sklar P, Anholt RRH, Snyder SH: The odorant-sensitive adenylate cyclase of olfactory receptor cells: Differential stimulation by distinct classes of odorants. J Biol Chem 1986, 261:15538-15543.

doi:10.1186/1749-8104-7-17

Cite this article as: Knott et al:: Olfactory discrimination largely persists in mice with defects in odorant receptor expression and axon guidance. Neural Development 2012 7:17.

\section{Submit your next manuscript to BioMed Central and take full advantage of:}

- Convenient online submission

- Thorough peer review

- No space constraints or color figure charges

- Immediate publication on acceptance

- Inclusion in PubMed, CAS, Scopus and Google Scholar

- Research which is freely available for redistribution 